\title{
Use and Care of Laboratory Animals
}

\author{
W. MAX CHAPMAN, M.D., M.P.H., and MALCOLM H. MERRILL, M.D., M.P.H.
}

\section{I} EGISLATION entitled, "Regulation of Use of Animals in Diagnostic Procedures and Medical Research" (1) has been in effect in California for more than 12 years. The following quotation from its preamble constitutes the State's policy in connection with this important function: "The public health and welfare depend on the humane use of animals for scientific advancement in the diagnosis and treatment of human and animal diseases, for education, for research in the advancement of veterinary, dental, medical and biologic sciences, for the research in animal and human nutrition and improvement and standardization of laboratory procedures of biologic products, pharmaceuticals and drugs."

We believe that the constructive accomplishment which can be achieved through State laws such as this has not received sufficient attention. Also, had more such laws been in effect, no basis would exist for promotion of Federal legislation (2). Some of the bills which have been considered recently in Congress were quite restrictive and would seriously impair research in which animals are used. The California law, on the other hand, provides protection for the welfare of laboratory animals, yet does not impose voluminous and obstructive administration requirements on their users.

The California law evolved from conferences beginning in 1948 among leaders in scientific education and in animal care who noted that each institution operated somewhat autonomously. Each organization developed its own rules and procedures for proper care of its animals, and there was little coordination of

Dr. Chapman is chief of the bureau of laboratory field services and Dr. Merrill is director, California State Department of Public Health, Berkeley. such operations. Furthermore, there was no criterion by which to determine whether such rules and procedures produced proper care for the animals. Issues arising could only result in differences of opinion which would have to be settled in the courts, with attendant loss of research time and money and perhaps loss of the legal action as well. Consequently, it was decided that administration of legally established rules by an officially established professional agency would be a reasonable means for achieving suitable status in animal care. The California State Department of Public Health was asked to accept this responsibility.

As first drafted, the laboratory animal care bill failed to pass the California Legislature in 1949. Two years later, however, a second bill, similar to the first, was received favorably and became law in 1951. The preamble to this law, quoted previously, describes the spirit in which it was conceived and in which it is administered.

\section{Administering the Law}

The law is administered by the department through its bureau of laboratory field services. The department employs a veterinarian to implement the law and also to act as consultant to research and educational institutions. The department has prepared and distributed guides based on the legal requirements for housing, feeding, and other care.

An advisory committee, whose members represent organizations interested in constructive use of laboratory animals, assists the department in creating policies and procedures for protection of the animals during research or other work.

At present more than 300 laboratories, having a total of more than 700,000 animals, are li- 
censed. Each laboratory has its approval renewed annually, after reporting to the department the number and types of animals kept and the number used during the period. Each laboratory also keeps a file of the number and types of animals used per month as well as the purposes for which they were used. Department representatives visit the laboratories periodically, sometimes by appointment for consultation and sometimes unannounced to observe facilities and procedures.

An important feature of the California law is its protection of animal users against harrassment by capriciously critical persons. When complaints are made, the State department of public health investigates according to legal requirements. If such complaints are found to lack substance, the respondent institutions are released from subsequent legal proceedings. Thus only the health department is involved, and necessary and proper research or other work can be continued without interruption and without appropriation of time and money by the institutions for their defense.

As a specific example, the State department of public health, with legal counsel from the State's attorney general, once participated in a lengthy legal action. This action necessitated presentation of the facts disclosed by departmental investigation to the State board of public health in its meeting of April 22, 1960. Following this the issue was considered by the superior court (3), and finally by the district court of appeals (4). Since the departmental investigation found that the original complaint lacked substance, no representative of the defendant institution had to participate in these proceedings at any time. Although the monetary value of the effort and time spent in investigation, in travel, and in court by department representatives and their legal counselors was considerable, none of these obligations was required of the defendant institution or its research program.

One of the features in the law is a provision permitting the State board of public health to adopt regulations (5) to amplify certain provisions in the law and to provide for better administration. The law and regulations provide that anyone may file a complaint under this animal care law against any licensed person or institution. The procedure to be followed is given in one section of the law: "The board may, upon its own motion, and shall upon the verified complaint in writing of any person, investigate the actions of any person keeping or using animals for research or diagnostic purposes within this State, and it may temporarily suspend or permanently revoke a certificate of approval at any time where the holder of such a certificate, within the immediately preceding 3 years, while a holder of a certificate of approval, in performing or attempting to perform any of the acts within the scope of this chapter, has been guilty of the breach of any of the provisions of this chapter or of any reasonable rule or regulation adopted by the board for the purpose of carrying out the provisions of this chapter."

The regulations amplify this requirement: "Anyone who files a complaint to the Department against an individual, or person, violating this law shall supply in writing specific information regarding the alleged violation, or violations. Such complaint shall include the time, date, place, individual, or person involved; and the names of other witnesses who may be called to testify. This statement must be in the form of a sworn affidavit and must be notarized."

\section{Complaints}

As indicated by the preceding quotation, any person may file a formal complaint against a licensee providing the complaint is in the required form and contains all the necessary information required by law. Receipt by the department of such sworn complaints requires only that the department investigate, and subsequent action depends entirely on what it finds in the course of the investigation. Dr. Orland Soave, veterinarian in charge of administering the California law in its early years stated (6):

"The investigation into the charges set forth in a complaint should be thorough and impartial. All persons named in the complaint should be interviewed and their oral statements written down for the record. The methods used by the particular institution for handling and caring for animals must be minutely scrutinized, including pre-operative and post-operative care in the case of animals used for surgery. Sanitation, sacrifice, and disposal of animals, as well as the significance of the work being done should 
also be investigated. A frequent charge made in relation to the use of animals in research is that they were used for no specific purpose or for one with no scientific import.

"Both factions must be interviewed including the complainant and the respondent. The investigation by the health department is directed toward determining if violations of the law have occurred. If violations are found, it must be determined whether they are of sufficient significance to warrant suspension or revocation of license. When all of the evidence, documents, and information have been collected, a complete report is prepared for review by the State board of public health. This report should include recommendations on what actions are believed to be applicable by the department for the particular case in question. If the investigation did not uncover information or evidence constituting a significant breach of the laws and regulations, a resolution may be adopted by the board, closing the case. On the other hand, if the recommendation of the board is to suspend or revoke the license, a formal hearing must be held. It should be repeated and emphasized that the mere filing of a complaint with the department does not automatically require a formal hearing. Such complaints require only investigation as the first step. If complainants are not satisfied with the investigation by the department and in the action taken by the board, they may petition the court for a writ of mandate. In such an action the assumption is made by the petitioner that the department and the board were derelict or negligent in their duties in respect to handling and investigating the case. In such instances the judge of the superior court in which such cases are considered, will examine the evidence collected by the department and the investigation made by its personnel. If in the judge's opinion this has been thorough and sufficiently inclusive, with no indication of prejudice, he may decide to uphold the action of the board and state that the case is closed. The complainant then has the opportunity to appeal the case if he chooses to follow this course."

In the administration of this law, the department has received many informal complaints, but only two formal ones $(\%, 8)$. Most of the informal complaints are direct reports of in- cidents, or allegations against specified institutions involving stated principles or procedures. For example, the use of animals in high school science fairs has been questioned. Some say high school students are not mature enough to understand the moral issues associated with such studies. Others wonder whether the high schools are equipped to provide adequate animal care, particularly over weekends and during vacations. Other examples include occasional incidents where science-minded students maintain animals for experimental work at home. With the encouragement and assistance of friendly mentors, some fairly ambitious projects have been undertaken. Reports of these reach the department in a variety of ways. On several occasions local newspapers have favorably publicized these investigations. While the ambition and interest of young students is praiseworthy, the department has had to take prompt steps to insure that the welfare of the animals was protected.

People with sincere concern over the welfare of laboratory animals occasionally visit research and other laboratories. If they question the procedures they observe, their questions are brought to the attention of the department where action for correction is initiated, if indicated, or the procedures are explained as proper for the particular situation.

The following two situations are such instances. First, a lack of exercise area for dogs was pointed out by an observer of several institutions. Second, the design and usefulness of experiments was questioned by another. In the first instance, new designs for dog quarters were planned and, in the second, the detail of the experiment was explained by the department veterinarian, and the reasons for its usefulness were clarified.

Other dissenters prepare emotionally tinged communications which paint a black picture, and they say that most investigators in science and medicine are hopelessly calloused in their feelings toward animals. Many of these communications come from persons who seem to have followed unquestioningly the leadership of promoters of various organizations. There is a similarity among such complaints which suggests only minor variations from a centrally supplied theme. 
While there have been more than a hundred complaints and communications of a kind classified legally as informal, each cne has received careful consideration and appropriate attention. Some complaints or inquiries referred to a situation which inspired several similar communications from additional sources. Others were in the form of petitions containing a list of signatures. The two formal complaints submitted were thoroughly investigated by department representatives with legal assistance provided by the California attorney general. The investigations covered several months of inquiry, inspection, and review of documents, Both formal complaints were based on the continuous submission of reports and photographs over a period of several weeks by an animal caretaker. These reports were sent to his basic employer in the headquarters of a national organization. His secondary employers were the institutions where he worked, but they were unaware of his basic affiliation. All events reported had occurred more than a year prior to the complaints. Investigations revealed no significant violations of the law. A report of the investigation was the basis for resolutions by the State board of public health to take no further action on the issues. In one complaint the national organization attempted to force further action through the courts. In both the superior court (3) and the court of appeals (4) the action of the department was upheld. Although a case was filed with the superior court in reference to the second complaint, no further action has resulted to date.

\section{Amplifying Regulations}

The law recognizes the use of laboratory animals as a serious responsibility. In addition to the basic records of animals already mentioned, it is clear that the legislature intended supervision of animals in licensed institutions by highly qualified officials. The law states in part: "The department shall make reasonable rules and regulations to carry out the purposes of this chapter. Such regulations shall include requirements for satisfactory shelter, food, sanitation, recordkeeping, and for the humane treatment of animals by persons authorized by the department to keep or to use animals."
The regulations amplify these criteria as follows: "Each applicant for certification shall designate an individual who will be directly responsible for the use and care of animals and for making appropriate reports thereof. Such individuals shall occupy a responsible position of authority in the applicant organization. The department may deny any application unless it is satisfied that the responsible individual so designated is qualified and will require that the animals kept or used by the applicant be used and cared for in a humane manner acceptable to this department."

An extension of the law, not originally contemplated, was found to include high schools and junior colleges. Dr. Martin Goetz, the veterinarian presently administering the provisions of the law, has clarified the responsibilities of these institutions in a series of questions and answers directed to appropriate persons in the secondary school system (9). This publication is available to all teachers and school administrators. Following is a sample of the pamphlet's contents.

Q. Our students occasionally bring a pet animal into the classroom. Do we need a license for this?

A. No. When Johnny brings his pet rabbit to school for the day to "share" it with his classmates, such action cannot be defined as "animal experimentation." An experiment is the alteration of normal physiological function by infection, drugs, surgery, or radical change in diet or environment. In general, the State department of public health does not expect to license elementary schools.

Q. As a science instructor, what are my responsibilities in compliance with the animal care law?

A. Under the law the instructor assumes full responsibility for animal experiments (and his institution must be licensed).

This answer continues, outlining fully the total responsibility of the instructor in all phases of animal use and care and includes some of the moral issues. The publication also gives a source for obtaining additional information and a list of references covering animal care. Many other questions and answers clarify related problems.

The regulations leave no doubt about the 
quality of care required wherever laboratory animals are used. The following quotation from the regulations is illustrative: "Careful consideration shall be given to the bodily comfort of such animals. They shall be kindly treated, properly fed, and their quarters shall be clean, properly lighted and maintained at the proper temperature. Exception may be made to this rule only with expressed permission of the responsible individual. This permission may be granted only when the foregoing considerations would defeat the purpose of the work. Any operation likely to cause greater discomfort than the attending anesthetization shall not be undertaken until the animal be first rendered incapable of perceiving pain. At the conclusion of experiments, the animals must be killed painlessly or given care to minimize discomfort which is essentially equivalent, as determined by the department, to that rendered human beings following an operation." The regulations then continue with provisions covering animal quarters and feeding and the personnel who care for them.

The regulations establish a system of license fees, but this revenue falls short of covering the entire expense of administering the law. Remaining costs are borne by the department as part of its general functions.

\section{Summary}

The California law governing the use and care of laboratory animals has been constructively administered for more than 12 years.
The law has been tested in the courts and found to be sound and workable. The general level of animal care has improved, and this is expected to continue.

Consideration of this experience may be useful to other States. An expansion of this principle in the care of laboratory animals may possibly eliminate the need for Congressional action.

\section{REFERENCES}

(1) Regulation of use of animals in diagnostic procedures and medical research. California Health and Safety Code, ch. 5, Sect. 1650.

(2) U.S. Senate Bills Nos. 5533 and 1041. U.S. House Bills Nos. 4620, 4856, 4843, and 4840. All introduced into the 88th Cong. (1963).

(3) Entry of Judgment, Superior Court of California in and for the County of Alameda, July 1, 1960 (No. 307098).

(4) District Court of Appeals, State of California, 1st Appellate Dist., Div. 2. Judgment filed Jan. 15, 1962 (1 Civ. No. 19712).

(5) California Administrative Code, Title 17, Group 5.

(6) Soave, 0.: The California animal care law. Proceedings of the Animal Care Panel. Vol. II, No. 1, February 1961, pp. 5-12.

(7) Humane Society of the U.S. California Branch, Inc. $\nabla$ The College of Medical Evangelists. Served Oct. 26, 1959.

(8) Humane Society of the U.S. California Branch, Inc. $\nabla$ Leland Stanford Junior University. Complaint certified Feb. 1, 1960.

(9) Goetz, M. E.: Answers to questions regarding the regulation of use of laboratory animals in California secondary schools. State of California Department of Public Health, Berkeley, June 1962.

\section{PHS Grants for Smoking Control Research}

The Public Health Service has announced the award of 10 grants to support demonstrations and studies relating to cigarette smoking and its effects on health. As the first step in a long-range program based on the report of the Surgeon General's Advisory Committee on Smoking and Health, most of the projects are aimed at designs for reaching various population groups through the most effective educational methods. The grants, totaling almost $\$ 260,000$, have been awarded to organizations and agencies in the States of Arizona, California, Indiana, Massachusetts, North Dakota, Pennsylvania, and Virginia. 